Таким образом, в целом энтомофауна соцветий лопухов в условиях Елабужского района РТ достаточно однообразна, однако, как показали исследования, интенсивность заселения соцветий лопухов разных видов насекомыми-фитофагами различна. При совместном произрастании лопухов разных видов на одном участке фитофаги предпочитали заселять соцветия лопуха паутинистого.

\section{СПИСОК ЛИТЕРАТУРЫ:}

1. Басов В.М. Экология мух рода Urophora (Diptera, Tephritidae) в условиях Среднего Поволжья и Предуралья: монография. Елец: ЕГУ им. И.А. Бунина, 2006. 185 с.

2. Басов В.М., Толстогузова И.А. Мухи-пестрокрылки - специализированные фитофаги сорных васильков на пастбищах // Проблемы экологии в сельском хозяйстве. Пенза, 1993. Ч. 1. С. 61-62.

3. Басов В.М., Сапаев Е.А. К вопросу об эволюции пищевой специализации насекомых в связи с деятельностью человека // Известия Харьковского энтомологического общества. Харьков, 1996. Т. IV. Вып. 1-2. С. 5-13.

4. Басов В.М. Пестрокрылки (Diptera, Tephritidae) Среднего Поволжья и Предуралья // Вестн. Удм. унта. 1999. № 5. С. 33-45.

5. Басов В.М. Закономерности развития экологофаунистических комплексов (на примере мух-пест- рокрылок Среднего Поволжья и Предуралья): дис. ... д-ра биол. наук. Ижевск, 2001. 393 с.

6. Басов В.М., Басова Л.В. Консорционные связи васильков (Asteraceae, Centaurea) и их специализированных фитофагов мух-пестрокрылок (Diptera, Tephritidae) в Волжско-Камском крае // Вестник Удмуртского ун-та. 2000. № 5. С. 86-95.

7. Корнеев В.А. Новый вид мух-пестрокрылок рода Terellia (Diptera, Tephritidae) из Молдавии // Вестник зоологии. 1990. № 5. С. 67-69.

8. Воловник С.В. Жуки-долгоносики рода Larinus Dej. в фауне Запорожской области Украины (Coleoptera, Curculionoidea) // Биологический вестник Мелитопольского педагогического ун-та им. Богдана Хмельницкого. 2011. Вып. 1. С. 15-21.

9. Определитель растений Среднего Поволжья / В.В. Благовещенский, Ю.А. Стариков, Н.С. Раков, В.В. Старикова, В.С. Шустов. Л.: Наука, 1984. 392 с.

10. Eber S., Sturm P., Brandl R. Genetic and morphological variation among Biotypes of Tephritis bardanae // Biochemical Systematics and Ecology. 1991. Vol. 19. № 7. P. 549-557.

11. Басов B.M. Мухи-пестрокрылки (Diptera, Tephritidae) национального парка «Нижняя Кама»: биотопическое распространение, кормовые растения // Растительный и животный мир национального парка «Нижняя Кама»: сб. науч. тр. / под науч. ред. В.М. Басова. Ижевск, УдГУ, 1997. С. 85-113.

\title{
THE STUDY OF BURDOCK BLOSSOMS (ASTERACEAE: ARCTIUM) ENTOMOFAUNA IN THE YELABUGA DISTRICT OF THE REPUBLIC OF TATARSTAN
}

\author{
Leontyeva Irina Aleksandrovna, senior lecturer of Biology and Chemistry Department \\ Elabuga Institute (branch) of Kazan (Volga Region) Federal University \\ (Elabuga, Republic of Tatarstan, Russian Federation)
}

\begin{abstract}
The paper deals with the study of burdock blossoms (Asteraceae: Arctium) in the Yelabuga District of the Republic of Tatarstan where they are one of the most common species among the Compositae plants. They are mostly ruderal weeds, growing usually in waste places (abandoned orchards, wastelands, ravines, roadsides, river banks, dumps, walls of houses and fences, etc.). Some representatives of this genus are also found in the floodplain forests, sparse deciduous forests, clearings, forest edges.

The paper presents some results of study of species composition and population structure of phytophagous insects, developing in inflorescences of four species of burdock (Arctium tomentozum, Arctium minus, Arctium lappa, Arctium nemorosum) on the territory of Yelabuga District of the Republic of Tatarstan. Seven experimental sites were examined, their total area is 1,0 hectares. The basic research was conducted during the spring-summer period in 2015-2017 at the time of active flowering plants. There were three kinds of flies-petrotrak (Diptera: Tephritidae), one kind of flies-Midge (in Russian spp.), one kind of beetle-weevil (Curculionidae) and one species of moth (Gelechiidae).

Keywords: insects-phytophages; diversity; inflorescence; forage plant; Arctium tomentozum; Arctium minus; Arctium lappa; Arctium nemorosum; food specialization; fitofage; Diptera; Coleoptera; Lepidoptera; Yelabuga city; Yelabuga District; Republic of Tatarstan.
\end{abstract}

УДК 502.504

Статья поступила в редакцию 01.10.2017

\section{ЭКОЛОГИЧЕСКОЕ СОСТОЯНИЕ МАЛЫХ РЕК ИК И СЮНЬ ШАРАНСКОГО РАЙОНА РЕСПУБЛИКИ БАШКОРТОСТАН}

(C) 2017

Нафикова Эльвина Ришатовна, магистрант кафедры биологии и экологии

Исламова Айсылу Айратовна, кандидат биологических наук, доцент кафедры биологии и экологии Бирский филиал Башкирского государственного университета (2. Бирск, Республика Башкортостан, Российская Федеращия)

Аннотация. В настоящее время очень заметно сказывается отрицательное воздействие человека на водные экосистемы. Это в конечном счете отразилось в изменении гидрологического режима рек и озер. Резко 
ухудшились экологические условия на многих водных объектах. Обнаруживается и обострение водохозяйственных ситуаций, ухудшение условий водоиспользования из-за отсутствия научно обоснованных принципов природопользования на водосборе, а также количественное и качественное истощение водных ресурсов вследствие совокупного воздействия различных отраслей народного хозяйств.

Экологическое состояние водных объектов во многом зависит от внешнего воздействия, величина которого не должна превышать допустимых пределов. В этом случае экосистема сохраняет свою устойчивость. Определение допустимых воздействий - это задача, связанная с оценкой экологического состояния водного объекта при разных уровнях внешнего воздействия. В статье рассмотрен вопрос оценки экологического состояния рек и их устойчивости к загрязняющему воздействию; в частности, проведена оценка качества воды рек Ик и Сюнь в Шаранском районе Республике Башкортостана. Проведены физико-химические и органолептические анализы воды рек. Исследования проводились нами в сентябре - мае 2016-2017 гг. Анализ воды проводился в аналитической лаборатории Туймазинского межрайонного филиала ФБУЗ «Центр гигиены и эпидемиологии в Республике Башкортостан». Качество воды в реке оценено с помощью индекса Майера.

Ключевые слова: экологическое состояние рек; река Ик; река Сюнь; река Белая; Шаранский район; Республика Башкортостан; индекс Майера; предельно допустимая концентрация; биологическое потребление кислорода; химическое потребление кислорода; физико-химический анализ; маршрутно-экспедиционный метод; органолептический анализ; водные экосистемы; поверхностные воды; гидробионты.

\section{Введение}

На территории Российской Федерации практически все водные объекты подвержены антропогенному влиянию, качество воды большинства из них не отвечает нормативным требованиям [1]. Среди основных рек России наибольшими экологическими проблемами характеризуются Волга, Енисей. Они оцениваются как «загрязненные». Их крупные притоки - Ока, Кама, Иртыш, Миасс - оцениваются как «сильно загрязненные» [2].

Экологическое состояние поверхностных вод в Республике Башкортостане считается удовлетворительным. Насчитывается более 600 рек и 1000 озёр [3]. Самая известная из них река Белая - главная водная артерия Республики Башкортостан, левый и самый крупный приток реки Кама. Свое начало река Белая берет в Учалинском районе на высоте 745 м у подножия хребта Аваляк. Река принимает много притоков, справа в неё впадают Тирлян, Нура, Нугуш, Зилим, Сим с Инзером, Уфа с Айем и Юрюзанью, Быстрый Танып; слева - Уршак, Дема, Кармасан, Чермасан, База, Сюнь. Самым крупным из них является река Уфа [4].

Река Сюнь (Сэн) - левый приток реки Белой, берет начало южнее деревни Ново-Сабанаево Шаранского района, далее течет по Бакалинскому, Илишевскому районам Республики Башкортостан. Длина ее составляет 209 км, падение - 207 м, средняя высота 177 м.

В этом же районе республики протекает река Ик (Ык), левый приток реки Камы. Берет начало в 25 км южнее города Белебея, протекает по Белебеевскому, Ермекеевскому, Туймазинскому, Шаранскому районам Республики Башкортостан, затем по территории Республики Татарстан. Длина - 571 км, общее падение - 282 м, густота речной сети - 0,34 км/км ${ }^{2}$, средняя высота - 208 м [5].

Основными водными артериями Шаранского района являются реки Сюнь, Ик, а также Шаранка, Шалтык и более 30 притоков, большинство из которых являются притоками первого и второго порядков реки Сюнь. Каждая из них внесла свой вклад в развитие района, их образа жизни [6].

Исследования проводились нами в сентябре - мае 2016-2017 гг.

\section{Методы исследования}

При сборе материалов работы нами использовались следующие методы: маршрутно-экспедицион- ный, установление видовой принадлежности фауны с помощью определителей, метод расчета индекса Майера, физико-химические и органолептические методы анализа. Анализ воды проводился в аналитической лабораторий Туймазинского межрайонного филиала ФБУЗ «Центр гигиены и эпидемиологии в Республике Башкортостан» (Аттестат аккредитации испытательной лаборатории №POOC RU.000,510569).

Для изучения физико-химического состава и органолептических характеристик были отобраны пробы воды из рек Сюнь и Ик в районе сел Алпаево и Нижнезаитово и Алпаево, соответственно, в Шаранском районе Республике Башкортостана.

Отбор проб был произведен согласно требованиям ГОСТ 31861-2012 «Вода. Общие требования к отбору проб» [7]. Для оптимальной оценки экологического состояния поверхностных вод на территории Российской Федерации существует единые критерии оценки качества поверхностных вод, которые отражены в Санитарных правилах и нормах СанПин 2.1.5.980-00 «Гигиенические требования к охране поверхностных вод» [8].

Органолептические показатели исследуемых рек были определены по методикам П.В. Машкина [9] и Л.А. Коробейникова [10].

\section{Материалы \\ и результаты исследований}

Результаты оценки запаха воды, ее цветности и температуры в рамках рек Сюнь и Ик в Шаранском районе представлены в таблице (табл. 1).

Интенсивность запаха оценивают по 5-балльной шкале, запах воды в реке Ик и Сюнь в исследуемых точках соответствует 1 баллу, согласно шкале интенсивности запаха.

Температура воды в момент отбора пробы воды соответствовала сезону.

Результаты исследования показали, что в вода реках весной бесцветная, а осенью мутно-желтая, так как в ней содержатся взвешенные частицы глины, песка, ила, которые вымываются из грунта.

Следующим пунктом исследования был физикохимический анализ воды в реках Сюнь и Ик в Шаранском районе. Значения, показывающие состояния воды рек, представлены в таблице (табл. 2).

Присутствие органических веществ в воде повышает количество микроорганизмов и, соответственно, увеличивает значения БПК 5 . 
Нафикова Э.Р., Исламова А.А.

БПК - количество кислорода (в миллиграммах), необходимое для окисления в аэробных условиях, в результате происходящих в воде биологических процессов органических веществ, содержащихся в 1 л воды, определяется по результатам анализа изменения количества растворённого кислорода с течением времени при $20^{\circ} \mathrm{C}[11]$.

Таблица 1 - Органолептические показатели воды рек Ик и Сюнь

\begin{tabular}{|c|l|c|c|c|c|c|}
\hline $\begin{array}{c}\text { № } \\
\text { п/п }\end{array}$ & $\begin{array}{c}\text { Наименование } \\
\text { показателя }\end{array}$ & $\begin{array}{c}\text { ПДК СанПиН } \\
2.1 .5 .980-00\end{array}$ & $\begin{array}{c}\text { p. Сюнь, мг/л } \\
\text { (осень 2016 г.) }\end{array}$ & $\begin{array}{c}\text { p. Сюнь, мг/л } \\
\text { (весна 2017 г.) }\end{array}$ & $\begin{array}{c}\text { p. Ик, мГ/л } \\
\text { (осень 2016 г.) }\end{array}$ & $\begin{array}{c}\text { p. Ик, мг/л } \\
(\text { весна 2017 г.) }\end{array}$ \\
\hline 1 & Запах & 0 & 1 & 1 & 1 & 1 \\
\hline 2 & Цветность & бесцветный & мутно-желтая & бесцветный & мутно-желтая & бесцветный \\
\hline 3 & Температура & - & +16 & +9 & +13 & +11 \\
\hline
\end{tabular}

Таблица 2 - Результаты лабораторных испытаний качества воды рек Ик и Сюнь

\begin{tabular}{|c|c|c|c|c|c|c|}
\hline $\begin{array}{l}\text { № } \\
\Pi / \Pi\end{array}$ & $\begin{array}{c}\text { Наименование } \\
\text { показателя }\end{array}$ & $\begin{array}{c}\text { ПДК, мг/л } \\
\text { (СанПиН } \\
2.1 .5 .980-00)\end{array}$ & $\begin{array}{c}\text { р. Сюнь, мг/л } \\
\text { (осень } 2016 \text { г.) }\end{array}$ & $\begin{array}{l}\text { p. Сюнь, мг/л } \\
\text { (весна } 2017 \text { г.) }\end{array}$ & $\begin{array}{c}\text { р. Ик, мг/л } \\
\text { (осень } 2016 \text { г.) }\end{array}$ & $\begin{array}{c}\text { p. Ик, мг/л } \\
\text { (весна } 2017 \text { г.) }\end{array}$ \\
\hline 5 & $\mathrm{pH}$ & $6,5-8,5$ & 7,6 & 7,15 & 7,5 & 8,0 \\
\hline 6 & $\begin{array}{l}\text { Взвешенные } \\
\text { вещества }\end{array}$ & 0,75 & 1,615 & 1,700 & 1,610 & 1,675 \\
\hline 7 & ХПК & 30 & 13,475 & 13,891 & 13,465 & 13,775 \\
\hline 8 & БПК полное & 4 & 5,450 & 5,301 & 4,800 & 4,688 \\
\hline 9 & Ион аммония & 1,5 & 0,750 & 0,300 & 0,550 & 0,270 \\
\hline 10 & Нитрат-ион & 45 & 4,550 & 5,175 & 3,750 & 3,550 \\
\hline 11 & Нитрит-ион & 3,3 & 3,076 & 3,396 & 3,307 & 4,080 \\
\hline 12 & Фосфат-ион & 1,14 & 1,187 & 1,200 & 1,200 & 1,215 \\
\hline 13 & Сульфат-ион & 500 & 212,000 & 220,000 & 213,000 & 200,000 \\
\hline 14 & Хлорид-ион & 300 & 103,515 & 110,717 & 100,525 & 109,610 \\
\hline 15 & Нефтепродукты & 0,5 & 0,073 & 0,091 & 0,090 & 0,110 \\
\hline 16 & СПАВ & 0,10 & 0,028 & 0,026 & 0,022 & 0,019 \\
\hline 17 & Железо & 0,3 & 0,516 & 0,529 & 0,329 & 0,363 \\
\hline 18 & Хром 3 вален. & 0,075 & 0,008 & 0,007 & 0,008 & 0,007 \\
\hline 19 & Хром 6 вален. & 0,05 & 0,008 & 0,007 & 0,008 & 0,007 \\
\hline 20 & Медь & 0,1 & 0,001 & 0,001 & 0,001 & 0,001 \\
\hline 21 & Цинк & 1 & не обнаружено & не обнаружено & не обнаружено & не обнаружено \\
\hline 22 & Никель & 0,02 & 0,01 & 0,01 & 0,01 & 0,01 \\
\hline 23 & Свинец & 0,005 & не обнаружено & не обнаружено & не обнаружено & не обнаружено \\
\hline 24 & Кадмий & 0,1 & не обнаружено & не обнаружено & не обнаружено & не обнаружено \\
\hline 25 & Марганец & 0,1 & 0,01 & 0,01 & 0,01 & 0,01 \\
\hline 26 & Алюминий & 0,2 & 0,018 & 0,017 & 0,021 & 0,020 \\
\hline 27 & Фенолы & 0,001 & 0,001 & 0,001 & 0,001 & 0,002 \\
\hline 28 & Сухой остаток & 1000 & 400,050 & 390,550 & 533,001 & 447,01 \\
\hline 29 & Жиры & не нормируется & 0,121 & 0,125 & 0,125 & 0,130 \\
\hline 30 & $\begin{array}{l}\text { Растворенный } \\
\text { кислород }\end{array}$ & не менее 4 & 7,5 & 7,5 & 7,5 & 7,5 \\
\hline
\end{tabular}

Для проб воды обеих исследуемых рек было характерно незначительное превышение значений ПДК. Вода из проб, отобранных весной, характеризовалась более низкими значениями БПК по сравнению с осенними (рис. 1). Повышенный уровень БПК при проведении анализа в поверхностных водах говорит о том, что воде требуется много кислорода для окисления вредных примесей. А значит, количество этих самых примесей также велико.

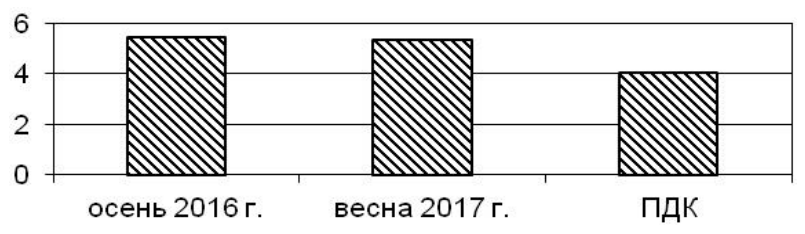

Рисунок 1 - БПК в в пробе воды реки Сюнь

Повышенное содержание нитритов указывает на усиление процессов разложения органических веществ в условиях медленного окисления нитритионов в нитрат-ионы, что свидетельствует об орга- ническом загрязнении водоема. Нитриты негативно влияют на химические и гидробиологические показатели воды, что в конечном итоге отражается на гидробионтах. Их интоксикация нитритами вызывает тяжелейшие сдвиги в метаболизме, усиление процессов перекисного окисления липидов, подавление систем антиоксидантной защиты организма с последующими деструктивными процессами на уровне ферментативных реакций, гуморальных факторов регуляции и клеточных мембран. Часто повторяющаяся и длительная интоксикация организма у гидробионтов, даже небольшими дозами токсикантов, сопровождается стрессами, приводит к истощению гипофизарноадреналовой системы, подрыву защитных сил организма и ослаблению клеточного иммунитета [12-14].

Сезонные колебания нитритов характеризуются отсутствием их зимой и появлением весной при разложении неживого органического вещества. Наибольшая концентрация нитритов наблюдается в конце лета, их присутствие связано с активностью фитопланктона (установлена способность диатомовых 
и зеленых водорослей восстанавливать нитраты до нитритов). Осенью содержание нитритов уменьшается [15] (рис. 2).

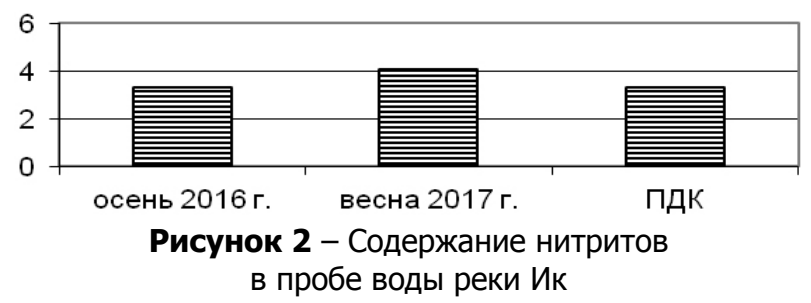

Количество взвешенных веществ (органические и неорганические частицы, содержащиеся в воде во взвешенном состоянии) превышают норму как в р. Сюнь, так и в р. Ик. Говоря о взвешенных веществах, можно сделать вывод, что р. Ик и Сюнь, протекая по местности, где берега не имеют каменной «подложки», постоянно омывают земляные, глинистые берега, смывают различные примеси, тем самым ухудшая данный показатель, повсеместно используемый при оценке качества поверхностных вод (рис. 3).

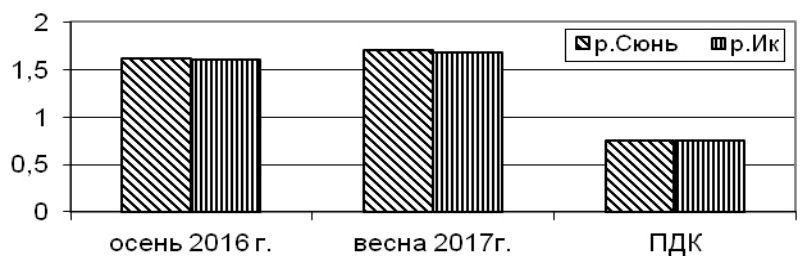

Рисунок 3 - Содержание взвешенных веществ в пробе воды рек Ик и Сюнь

Проведенное исследование показало, что в воде реки Сюнь содержание ионов железа превышает предельно допустимую концентрацию почти на 70\%. Причем это значение практически не изменяется в зависимости от времени года. Река Ик по данному параметру относительно благополучна, концентрация ионов железа ПДК превышена незначительно (рис. 4).

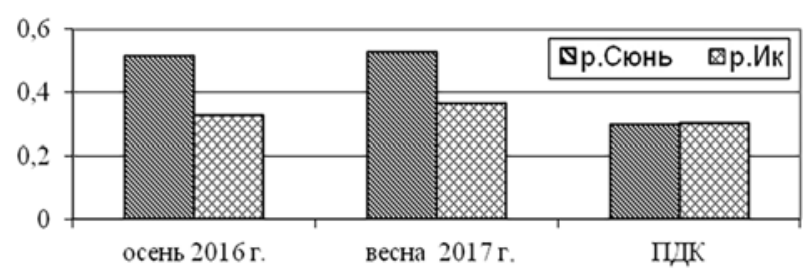

Рисунок 4 - Содержание ионов железа в пробе воды рек Сюнь и Ик

Ионы железа попадают в воду при растворении горных пород. Насыщенными ионов железа оказываются подземные воды в толщах юрских глин. В глинах много пирита $\left(\mathrm{FeS}_{2}\right)$, и ионы железа из него относительно легко переходят в воду [16].

Также значительное количество ионов железа в поверхностные воды поступает с сельскохозяйственными стоками, что, предположительно, является одной из основных причин превышения ПДК по указанному показателю [17].

Для получения более полной картины экологического состояния рек Ик и Сюнь были применены также биологические методы, в частности метод оценки качества воды по Майеру, основанный на качественном и количественном анализе обитающих в водоеме гидробионтов (табл. 3, 4) [18].

Водоему присваивается I класс качества в том случае, если индекс Майера окажется равным 22. Водоем относится ко 2 классу качества, если индекс Майера оказался в интервале от 17 до 21. Значения суммы от 11 до 16 говорят о 3 классе качества - умеренная загрязненность. Все значения меньше 11 характеризуют водоем как грязный - 4-7 классы качества [19].

Таблица 3 - Оценка качества воды по индексу Майера рек Сюнь и Ик

\begin{tabular}{|l|c|c|}
\hline \multirow{2}{*}{\multicolumn{1}{|c|}{ Обитатели воды }} & \multicolumn{2}{c|}{$\begin{array}{c}\text { Количество } \\
\text { организмов }\end{array}$} \\
\cline { 2 - 3 } & Сюнь & Ик \\
\hline Обитатели чистых вод: & - & 3 \\
\hline Личинки веснянок & 4 & 2 \\
\hline Личинки поденок & - & 4 \\
\hline Личинки ручейников & 1 & 3 \\
\hline Личинки вислокрылок & \\
\hline
\end{tabular}

Организмы средней степени чувствительности:

\begin{tabular}{|l|c|c|}
\hline Бокоплав & 7 & - \\
\hline Речной рак & - & 3 \\
\hline Личинки стрекоз & 5 & 1 \\
\hline Личинки комаров-долгоножек & - & - \\
\hline Моллюски-катушки & 4 & 2 \\
\hline Моллюски-живородки & 2 & 1 \\
\hline Обитатели загрязненных водоемов: \\
\hline Личинки комаров-звонцов & - & - \\
\hline Пиявки & - & \\
\hline Водяной ослик & - & \\
\hline Прудовик & 3 & 3 \\
\hline Личинки мошки & 1 & \\
\hline Малощетинковые черви & - & \\
\hline
\end{tabular}

В пробах воды из реки Сюнь были обнаружены организмы средней степени чувствительности: бокоплавы, личинки стрекоз, катушки, моллюски-живородки. Индекс Майера в исследуемом районе в реке Сюнь оказался равен 16, это свидетельствует о том, что вода 3-го класса качества.

В реке Ик были обнаружены следующие виды животных биоиндикаторов: личинки ручейников, личинки поденок, речной рак, двустворчатые моллюски, моллюски-катушки, моллюски-живородки, личинки поденок. Индекс Майера составил 21, водоем характеризуется как умеренно загрязненный 2-го класса качества [20].

Выводы
По результатам исследования установлено, что в составе воды из реки Сюнь такие показатели, как БПК 5 , концентрация ионов железа и содержание взвешенных веществ, превышают предельно допустимую концентрацию, установленную в нормативном документе СанПиН2.1.5.980-00 «Гигиенические требования к охране поверхностных вод». Индекс Майера в реке Сюнь составил 16, вода 3-го класса качества воды.

Для реки Ик установлено превышение предельно допустимой концентрации по таким показателям, как нитрит-ионы, ионы железа, взвешенные вещества. Индекс Майера в реке составил 21, водоем характеризуется как умеренно загрязненный 2-го класса качества.

В целом экологическое состояние реки Ик на момент исследования является более благополучным по сравнению с рекой Сюнь, хотя оба водотока испытывают примерно одинаковый уровень антропогенной нагрузки. Полученные данные могут быть применены при более масштабном экологическом мониторинге рек Республики Башкортостан. 


\section{СПИСОК ЛИТЕРАТУРЫ:}

1. Станковский А. Экологические проблемы водных ресурсов. Омск: Наука, 2004. 183 с.

2. Шикломанов И.А. Водные ресурсы России и их использование. СПб.: Государственный гидрологический институт, 2008. 152 с.

3. Балков А.В. Водные ресурсы Башкирии. Уфа: Просвещение, 2008. 355 с.

4. Гареев А.М. Реки и озера Башкортостана. Уфа: Китап, 2011. 259 с.

5. Гареев А.М. Водные ресурсы Башкирии и их состояние в будущем. Уфа: Китап, 2003. 204 с.

6. Миннигалиев Н.Х. Край родной, навек любимый. Уфа: Китап, 2011. 358 с.

7. ГОСТ 31861-2012 Вода. Общие требования к отбору проб. М.: Стандартинформ, 2013. 32 с.

8. Санитарные правила и нормы СанПиН 2.1.5.980-00 «Гигиенические требования к охране поверхностных вод». Утв. главным государственным санитарным врачом РФ Г.Г. Онищенко 22.06.2000 г.

9. Машкин П.В. Биологические методы оценки состояния водных экосистем. Омск: Наука, 1996. 34 с.

10. Коробейникова Л.А. Комплексная экологическая практика школьников и студентов: учебнометодическое пособие. СПб., 2002. 268 с.
11. Хараева Г.И. Экологический мониторинг. УланУдэ: Изд-во ВСГТУ, 2004. 77 с.

12. Черкесова Д.У.,, Шахназарова А.Б. Экология животных. Махачкала: Юг России, 1990. 131 с.

13. Ажипа Я.И., Реутов В.П., Каюшин П.П. Экологические и медико-биологические аспекты проблемы загрязнения окружающей среды нитратами и нитритами // Физиология человека. 1990. Т. 16, № 3. С. $131-150$.

14. Велдре И.А.Токсическое воздействие нитратов на рыб. Экология 1990. С. 71-73.

15. Логинова Е.В., Лопух П.С. Гидроэкология. Мн.: БГУ, 2011. $78 \mathrm{c.}$

16. Абдрахманов Р.Ф., Попов В.Г. Ионообменная концепция в генетической гидрохимии. Уфа: Гилем $2013.357 \mathrm{c}$.

17. Москвин А.Г. Экология водоемов России. Рязань: Школа-Пресс, 1999. 134 с.

18. Сибагатуллина А.М., Мазуркин П.М. Измерение загрязненности речной воды. М.: Изд-во «Академия естествознания», 2009. 216 с.

19. Абдрахманов Р.Ф. Гидрогеоэкология Башкортостана. Уфа: Информ, 2005. 344 с.

20. Акимушкин И.И. Мир животных: Беспозвоночные. М.: Мысль, 1992. 382 с.

\title{
ECOLOGICAL CONDITION OF THE SMALL RIVERS IK AND SYUN IN THE SHARANSKY DISTRICT OF THE REPUBLIC OF BASHKORTOSTAN
}

\author{
Nafikova Elvina Rishatovna, master student of Biology and Ecology Department \\ Islamova Aysylu Airatowna, candidate of biological sciences, \\ associate professor of Biology and Ecology Department \\ Birsk branch of Bashkir State University (Birsk, Republic of Bashkortostan, Russian Federation)
}

Abstract. Currently the negative impact of man on aquatic ecosystems is very noticeable. This, in the final analysis, was reflected in the change in the hydrological regime of rivers and lakes. Environmental conditions in many water bodies deteriorated sharply. There are also acute exacerbations of water management situations, deterioration of water use conditions due to the lack of scientifically based principles of nature management in the catchment area, and quantitative and qualitative depletion of water resources due to the combined impact of various sectors of the national economy The ecological state of water bodies largely depends on external influences, the magnitude of which should not exceed the permissible limits. In this case, the ecosystem maintains its stability. The paper deals with the assessment of the ecological state of rivers and their resistance to polluting effects, in particular, an assessment of the quality of the water of the Ik and Syun rivers in the Sharansky District of the Republic of Bashkortostan. Physicochemical and organoleptic analyses of the rivers have been carried out. The research was conducted in SeptemberMay 2016-2017. The analysis of the water was carried out in the analytical laboratories of the Tuimazy inter-district branch of the FBU «Center for Hygiene and Epidemiology in the Republic of Bashkortostan». The water quality in the river was estimated using the Mayer index.

Keywords: ecological condition of rivers; river Ik; Syun River; Belaya River; Sharansky District; Republic of Bashkortostan; Mayer index; maximum permissible concentration; biological oxygen consumption; chemical oxygen consumption: physical and chemical analysis; route-forwarding; organoleptic analysis; aquatic ecosystems; surface waters; hydrobionts.

УДК 598.112:591.16:591.13

Статья поступила в редакцию 03.10.2017

\section{ОТДЕЛЬНЫЕ АСПЕКТЫ БИОЛОГИИ TAКYDROMUS WOLTERI И TAKYDROMUS AMURENSIS} (C) 2017

Портнягина Екатерина Юрьевна, аспирант кафедры экологии Дальневосточный федеральный университет (2. Владивосток, Российская Федерачия)

Маслова Ирина Владимировна, кандидат биологических наук, ведущий инженер лаборатории териологии Федеральный научный иентр биоразнообразия наземной биоты Восточной Азии ДВО РАН

(2. Владивосток, Российская Федераџия)

Аннотащия. В работе представлены сведения об отдельных аспектах размножения и питания двух малоизученных видов ящериц рода Takydromus - Takydromus wolteri u Takydromus amurensis - в северновосточной части их ареала (Приморский край, Дальний Восток, Россия). Использованный в публикации ма- 